\title{
MECANISMO DA CONTRAÇÃO MUSCULAR
}

\author{
JosÉ ANTonio LeVY* \\ Aron J. Diament ** Sylvio Saraiva**
}

A fibra muscular estriada é constituida por uma membrana (sarcolema), pelo citoplasma indiferenciado (sarcoplasma), pelas miofibrilas e pelos núcleos subsarcolêmicos. O sarcolema, de importância fundamental para a contração muscular, constitui a membrana que separa o meio interno, rico em ions potássio, e o meio externo, rico em íons sódio. Quando integra, esta membrana permite apenas a passagem de íons positivos, e só no sentido de dentro para fora; em vista disso, a disposição das cargas elétricas vizinhas a esta membrana adquire característica especial, isto é, as cargas positivas ficam para fora do sarcolema e as cargas negativas, para dentro (fig. 1).

Fig. 1 - Representação esquemática da membrana celular em repouso, com a distribuiçio das cargas elétricas em reiaçĩo aos meios interno e externo.

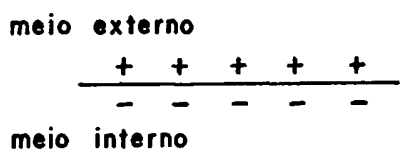

meio interno

Uma membrana com tal disposição das cargas elétricas ao seu redor, diz-se polarizada ${ }^{3}$; ela será despolarizada por qualquer causa química, física ou mecânica capaz de alterar esta disposição. $O$ estímulo representado pelo influxo nervoso é responsável pela produção de acetilcolina ao nível da terminação dos nervos nos músculos; a acetilcolina despolariza a membrana sarcolêmica e, quando esta despolarização atinge um certo limiar, forma-se uma onda de despolarização, que se propaga pela fibra muscular, provocando a contração. $\dot{E}$ um processo semelhante ao que se passa num rastilho de pólvora, em que a energia utilizada para a propagação do fogo é a própria pólvora colocada adiante. Assim, a onda de negatividade ca-

Trabalho da Clinica Neurológica da Fac. Med. da Univ. de São Paulo (Prof. Adherbal Tolosa).

* Assistente. ** Médicos auxiliares. 
minha pela fibra à custa das cargas elétricas positivas situadas adiante, do lado de fora da membrana (fig. 2).

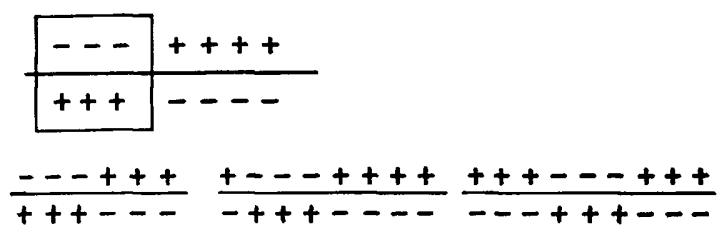

Fig. 2-Esquema da propagação do estimulo nervoso ao longo da membrana muscular.

Para que se processe a contração muscular, além do estimulo representado pelo influxo nervoso, cujo modo de ação é ainda discutido, concorrem dois outros elementos: a substância contrátil e a energia para contração.

A substância contrátil do músculo é representada pela actomiosina e a energia para a contração é fornecida pelo ATP (ácido adenosintrifosfórico), substância dotada de radicais fosfóricos ricos em energia e que produzem, ao se libertarem, cêrca de 10.000 cal. para cada radical fosfórico, sendo esta energia aproveitada sob a forma de energia química.

Actomiosina - A substância contrátil da miofibrila, ou actomiosina, não existe como tal na fibra muscular relaxada. Neste estado, encontramos filamentos de actina e de miosina, separados uns dos outros, dando a falsa impressão de estriação transversal vista nos exames histopatológicos dos músculos ${ }^{2,3}$. Os filamentos de actina e miosina são mantidos separados por meio de cargas elétricas, já que existe no músculo um verdadeiro equilíbrio iônico, os grupos carboxílicos destas proteínas sendo neutralizados pelos íons $\mathrm{K}^{1,4}$. A actina existe no músculo sob duas formas: a actina $G$ (globular) e a actina $F$ (fibrosa). Sòmente a actina $F$ é que se liga à miosina para formar a F-actomiosina ${ }^{1}$. A transformação da actina $G$ em actina $F$ depende da concentraçāo de íons $\mathrm{Na}^{+}, \mathrm{K}^{+}$e $\mathrm{Mg}^{+}+$. A miosina, por outro lado, só se une à actina $\mathrm{F}$ quando ligada ao íon $\mathrm{Mg}^{++}$, formando o miosinato de $\mathrm{Mg}^{3}$ (fig. 3). Isto demonstra a importância dêstes ions ( $\mathrm{Na}^{+}$, $\mathrm{K}^{+}$e $\mathrm{Mg}^{++}$) na formação da substância contrátil do músculo (F-actomiosina).

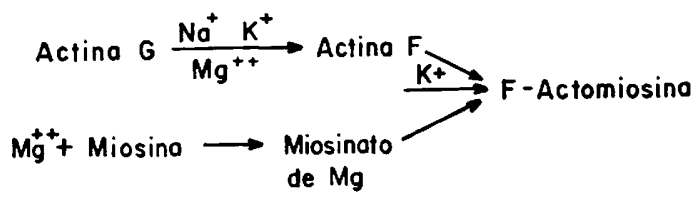

Fig. 3 - Esquema das reações quimicas que se verificaram na formaçióo da substância contrátil do músculo (actomiosina). 
Uma vez chegado o influxo nervoso, a fibra muscular se despolariza e rompe-se o equilibrio iônico existente em seu interior, formando-se, então, a F-actomiosina. Esta possui uma função chamada atepásica ${ }^{3}$, capaz de libertar radicais fosfóricos ligados ao ATP, radicais cuja energia será utilizada para que a contração se processe ${ }^{1}$. Nessas condições o ácido adenosintrifosfórico (ATP) é transformado no ácido adenosindifosfórico ou ADP:

$$
\text { F. Actomiosina }+\mathrm{ATP} \longrightarrow \text { Actina }+ \text { Miosina }+\mathrm{ADP}+\mathrm{PO}_{\mathbf{t}} \mathrm{H}+\text { energia }
$$

Entretanto, o músculo seria uma "máquina" de péssimo rendimento se não reaproveitasse as radicais fosfóricos e o ADP libertados, para a ressíntese do ATP. O ATP é formado, no músculo, por dois mecanismos (fig. 4)²:

a) Combinação da fosfocreatina com o ADP, resultando a formação de ATP e creatina, segundo a reação:

$$
\text { ADP + fosfocreatina } \longleftrightarrow \text { ATP + creatina }
$$

Esta reação, que é reversivel, constitui um meio de poupança de ATP pelo músculo, o qual pode, nos momentos de grande necessidade, aproveitá-lo novamente.

b) Normalmente, entretanto, o ATP muscular é formado a partir do ADP e do fósforo rico em energia no decorrer do mecanismo da glicólise 2 . A glicólise é realizada em duas fases a partir do glicogênio muscular. Numa primeira fase, anaeróbia, há degradação da glicose até ácido pirúvico, o qual, quando persiste a falta de oxigênio, é transformado em ácido lático. A segunda fase, aeróbia, consiste nas reações do ciclo do ácido cítrico ou ciclo de Krebs que, partindo do ácido pirúvico, vai até a formação de $\mathrm{CO}_{2}$ e $\mathrm{H}_{2} \mathrm{O}$ (figs. 4 e 5 ).

Fig. 4 - Representação esquemática dos dois mecanismos de ressintese do ATP a partir da fosfocreatina e pela glicólise.

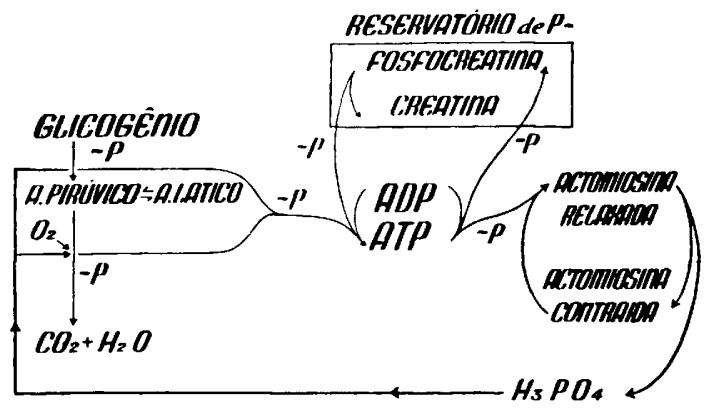




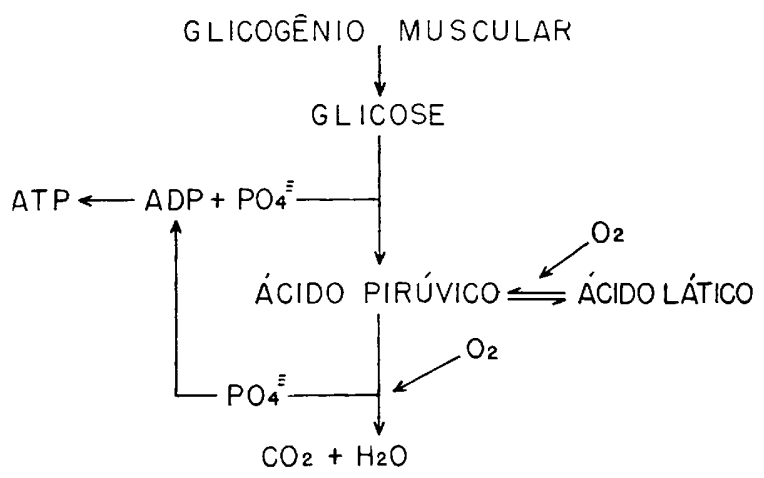

Fig. 5 - Representação esquemática da glicólise e sua relação com o mecanismo de produção do $A T P$.

Glicólise anaeróbia - Consiste em uma série de reações químicas por meio das quais o glicogênio muscular é transformado em ácido pirúvico. Nesta cadeia de reações há liberação de energia sob a forma de fosfatos que entram na síntese do ATP à custa do ADP. Como resultado dessa fase anaeróbia, para cada 6 átomos de carbônio, ou para cada molécula de glicose que reage, há formação de 3 moléculas de ATP, as quais fornecerão energia para a contração muscular.

O músculo pode, assim, funcionar durante algum tempo em anaerobiose; esta persistindo, haverá prođuçāo de ácido lático que se acumula no músculo, causando dor; entretanto, a reação é reversivel, em condições de oxigenação favoráveis, formando-se novamente ácido pirúvico a partir do ácido lático.

O tecido muscular é, no entanto, um tecido fundamentalmente aeróbio ${ }^{2}$. É na fase aeróbia da glicólise, na cadeia de reações conhecida como ciclo de Krebs, que se produz a maior quantidade do combustivel necessário para a contração muscular.

Ciclo aeróbio - No decorrer das reações do ciclo do ácido cítrico, a energia é liberada sob a forma de radicais fosfóricos que são aproveitados novamente para a sintese do ATP muscular. Para cada 6 carbônios ou 2 moléculas de ácido pirúvico formam-se 30 moléculas de ATP; cada uma destas fornece 10.000 cal.; portanto, cada 2 moléculas de ácido pirúvico propicia ao músculo a produção de 300.000 cal. Entretanto, esta energia não é liberada de uma vez e sim gradativamente, pois tal quantidade de energia "queimaria" as proteínas celulares.

O músculo é, portanto, um tecido essencialmente aeróbio. Quando o trabalho muscular é muito intenso, a quantidade de oxigênio utilizada pelo músculo é maior do que a quantidade que êste músculo pode receber por 
via sangüinea. Para que tal fato não ocasione imediatamente a anaerobiose, com conseqüente produção de ácido lático, o músculo possui uma reserva de oxigênio representada pela mioglobina.

A mioglobina, constituída por uma protoporfirina férrica, molécula semelhante à hemoglobina, tem muito maior capacidade do que esta para acumular oxigênio, o qual é liberado quando o músculo assim o necessita 1 . Se as condições de anaerobiose persistirem há interrupção da glicólise na fase de ácido pirúvico e ácido lático, reação reversível, como já vimos. Com a chegada de oxigênio, dentro de um certo tempo, antes que haja destruição do músculo, há novamente a formação de ácido pirúvico, iniciando-se, então, a fase aeróbia da glicólise, fase na qual grande contingente de energia sob a forma de fosfatos é fornecida para a ressintese do ATP.

Em sintese, pois, teremos: 1) estímulo nervoso e conseqüente despolarização da membrana; 2) rotura do equilíbrio iônico no interior da fibra muscular e conseqüente formação da actomiosina; 3) reação do ATP com a actomiosina, com produção de energia para a contração do músculo; 4) ressintese do ATP à custa do $\mathrm{ADP}$ e dos radicais fosfóricos ricos em energia, por dois mecanismos, isto é, reação do ADP com a fosfocreatina e aproveitamento dos radicais fosfóricos liberados nas fases aeróbia e anaeróbia da glicólise.

\section{RESUMO}

Os autores apresentam uma sintese dos conceitos atuais sôbre o mecanismo da contração muscular. Inicialmente estabelecem o conceito de membrana polarizada e despolarizada. Salientam a importância da substância contrátil (actomiosina) e da energia fornecida pelo ácido adenosintrifosfórico. São discutidas também as reaçōes químicas que se processam para a formação dessas substâncias, bem como o papel da mioglobina na contração muscular.

\section{SUMMARY}

\section{Mechanism of muscular contraction.}

The authors present a synthesis on the mechanism of muscle contraction. Firstly they establish the concept of polarizated and depolarizated membrane. They emphasize the importance of the contractile substance (actomyosin) and of the energy furnished by the adenosinetriphosphate. They also discuss on the chemical reactions which take place to form these substances, as well as on the part played by the myohaemoglobin in the muscular contraction. 


\section{REFERENCIAS}

1. ADAMS, R.; DENNY-BROWN, D.; PEARSON, C. - Enfermedades del Músculo. Tradução castelhana. Editora La Fragua, Buenos Aires, 1957. 2. BELL, G. H.; DAVIDSON, J. N.; SCARBOROUGH, H. - Textbook of Physiology and Biochemistry. Livingstone, Londres, 1959. 3. BUSCAINO, G. A. - Panorama patogenetico-biochimico delle distrophie musculari e della miotonia. Acta Neurol. (Nápoles), 14:1012400 (março-abril) 1959. 4. SZENT-GYORGYI, A. - What we need know about muscle. Neurology, 8:65-79 (janeiro) 1958.

Clinica Neurológica - Hospital das Clínicas da Fac. Med. da Univ. de São Paulo - Caixa Postal 3461 - São Paulo, Brasil. 